\title{
Fuzzy heuristic algorithm for simultaneous scheduling problems in flexible manufacturing sys- tem
}

\section{Prakash Babu Kanakavallia,b*, Vijaya Babu Vommi ${ }^{a}$ and Nageswara Rao Medikondu ${ }^{\mathrm{c}}$}

\author{
${ }^{a}$ Mechanical Engineering Department, COE, Andhra University, Visakhapatnam - 530 003, India \\ ${ }^{b}$ Mechanical Engineering Department, VRSEC, Vijayawada - 520007, India \\ ${ }^{c}$ Mechanical Engineering Department, KLEF, Guntur - 522502, India

\section{H R O N I C L E}

\section{A B S T R A C T}

\section{Article history:}

Received: July 20, 2018

Received in revised format: August 28, 2018

Accepted: September 15, 2018

Available online:

September 15, 2018

Keywords:

Scheduling

Automated Guided Vehicles

Fuzzy heuristic

Flexible manufacturing system and makespan
This paper addresses the flexible manufacturing system (FMS) problems considering both machines and automated guided vehicles (AGVs), simultaneously. A new fuzzy heuristic $(\mathrm{FH})$ is proposed for solving the simultaneous scheduling problem, in order to minimize the makespan by considering the available resources. For increasing the performance of FMS one of the important factors is scheduling AGV with an integral part of the machine scheduling activity. The algorithm is tested based on 82 benchmark problems and the achieved makespan are compared with other algorithms.

C 2018 by the authors; licensee Growing Science, Canada

\section{Introduction}

To achieve wide-variety and wide-range of products, flexible manufacturing system (FMS) is a sophisticated system in the area of manufacturing. While increasing the demand for goods, the management is motivated to find new ways to increase the output with available resources. FMS is the only alternative for conservative manufacturing system (Rathinam et al., 2015; Babu et al., 2018). FMS has a number of benefits such as cost reduction, better rate of utilization, reduced work levels in process, etc. Moreover, there are a number of drawbacks during the life cycle of FMS. These draw backs are likely scheduling, planning, control and design. During the operations of the scheduling, control problem is dynamic in FMS including assignment of AS/RS storage, routing of AGV, flexible parts and flexible tools. This paper concentrates mainly on FMS scheduling problems. Decisions are made not only based on the sequencing of the jobs but also according to routing the jobs in FMS scheduling. Apart from the machines, AGVs and AS/RS must be considered. For efficient production in FMS we need to employ AGVs as handling system. The efficiency of AGV depends on many factors like allocation of tasks to AGVs; specifying the path of AGVs and determining the start and finish times of the assigned work.

* Corresponding author. Tel. : +919030715154

E-mail address: prakashnitc@gmail.com (P. B. Kanakavalli)

(C) 2018 by the authors; licensee Growing Science, Canada doi: $10.5267 /$ j.msl.2018.9.008 


\section{Literature review}

FMS consists of NC machine, AGVs and computer network. This network works through controlling and directing the whole system. Stecke (1985) described FMS design problems, FMS planning problems, FMS scheduling problems and FMS control problems. Kusiak (1986) developed a FMS scheduling system using a rule-based expert system following priority rules to scheduling jobs. If a job is not scheduled due to resource conflicts then decision table can be used to select alternative machines, tools, fixtures and material handlers. Han and McGinnis (1989) provided a discrete time control technique for a FMS cell based on a single-stage cell with some parallel workstations, machine failures, limited buffer capacities and various inputs from upstream cells. Nasr and Elsayed (1990) proposed a method to optimize the mean flow time in a job shop machining system with alternative machine tool routings. Sabuncuoglu et al. (1993) considered the FMS scheduling with both machine and AGV based on the due date criterion. These rules are evaluated under various experimental circumstances and the sensitivity of AGV was also investigated. Fang et al. (2011) adopted a shop scheduling approach by minimizing the completion time through a general multi-objective mixed-integer formulation. Pach et al. (2014) proposed reactive scheduling method for FMSs, which integrates the overall energy consumption of the production. The method was justified by the growing needs of manufacturers for energy-aware control subject to some environmental criteria in the context of high reactivity. Also real experiments were carried out to show the feasibility of the approach on a real system and validate the simulation results. Salido et al. (2017) followed rescheduling in job shop problems for sustainable manufacturing system with optimum completion time by looking into the performance measures such as mean flow time, makespan, maximum lateness and total absolute deviation from due dates.

\subsection{Scheduling and routing of AGV through heuristic algorithm}

During the past few decades, there has been tremendous efforts on developing heuristics to solve scheduling problems. Johnson's algorithm (1954) is among the first method for scheduling two machines. Each machine can handle only one item at a time and each item must be produced through machine one and machine two. The set up time plus work time for each item and for each machine is known. A simple decision rule is proposed by author for the optimal scheduling of the production for minimizing the total elapsed time and three machine problems is also discussed for restricted case. Palmer (1965) proposed a heuristic for the flow shop scheduling with makespan minimization. In this connection, number of items must pass through a number of processes in the same order and it was suggested that the optimum scheduling may be approximated by giving priority to items according to the extent to which process time increases with process number in order. Campbell et al. (1970) proposed a simple algorithm for large sequencing problems without the use of computers. It produces approximate solutions to the $n$ job, $m$ machine sequencing problem where no passing is considered and the criterion is the minimum elapsed time up to $m$-1 sequences. Gupta (1971) proposed a functional heuristic algorithm to look for a fast approximate solution of $n$-job, $M$-machine flow shop scheduling problem under the assumptions that all jobs are processed on all machines in the same order and no passing of job is permitted. This algorithm can be used manually for reasonably large size problems and yielded solutions which are closed to optimal solutions than those obtained by palmer slope index algorithm. Nawaz et al. (1983) proposed a wellknown constructive heuristic for the general flow-shop scheduling giving top priority for a job with high total processing time on all machines. Ruiz and Stützle (2007) presented a greedy algorithm by applying iteratively in two phases' viz., destruction and construction. In destruction phases some jobs are eliminated from the incumbent solution, where as in construction phase, the eliminated jobs will be reinserted into the sequence using the well-known NEH construction heuristic. Vallada and Ruiz (2009) adopted a cooperative metaheuristic method for the permutation flow shop scheduling problem by considering the total tardiness and makespan individually. Heydari and Mohammadi (2010) proposed a fuzzy heuristic algorithm based on extended Johnson's algorithm for more than two machines problems. Performance of proposed algorithm for small size problems and the results were compared with optimum scheduling. Modrák and Pandian (2010) presented flow shop scheduling algorithm to multi stage job problems where 
simple priority rules were used to obtain solutions of minimum total processing time. The authors presented algorithm based on converting $m$-machine problem to a 2 -machine problem. Based on testing and comparison with other relevant methods, the proposed algorithm was offered as a competitive alternative for practical application when solving $n$-jobs and $m$-machines problems. Semančo and Modrák (2012) made a comparative study on constructive heuristics for makespan minimizing in the flow-shop scheduling. The computational experiment shows that the proposed algorithm was a feasible alternative for practical application when solving $n$-job and $m$-machine in flow-shop scheduling problems to give relatively good solutions in a short-time amount of Time. Zupan et al. (2016) adopted hybrid algorithm which is a combination of heuristic algorithm extended with priority rules, discrete event simulation and genetics algorithm. The simulation result for the proposed model was the optimal sequence of the selected orders for the selected time interval while taking into account three criteria: the minimum flow time of all orders, the maximum average utilization of workplaces, and the minimum waiting time of the orders. This paper proposes a fuzzy heuristic algorithm for solving simultaneous scheduling problems in FMS.

\section{Problem statement}

The FMS environment, example problem assumptions, input data for FMS, objective function and vehicle heuristic algorithm for the current work are given below.

\subsection{FMS Environment}

The FMS environments with some considerations are given below:

1. Flexible numerical controlled (NC) machines, furnished with automatic tool changing.

2. An automated material handling systems (MHS) such as conveyors, carts, Industrial robots, AGVs or a combination of them are used to move parts and tools.

3. The entry and exit of the parts take place through Loading/Unloading (L/U) stations.

4. Use coordinate measuring machines for inspection purpose.

5. Sufficient buffer space is provided to near by the machine to store the raw and semi-finished work pieces.

6. Provide tool magazine to store the tools on the machine.

7. A hierarchical control system (HCS) is used to NC machines, tools and MHS.

8. Two operations of a job cannot be done simultaneously.

9. Machine cannot be performing more than one operation at a time.

10. Anticipation of operations or AGV trips is not permitted.

11. The duration for AGVs trips is sequence dependent.

\subsection{Assumptions}

The FMS environments with following assumptions are given below:

1. Initially all the vehicles start from the load/unload station.

2. The number and type of machines are known.

3. Each machine performs more than one operation.

4. Both the processing times and travel times are known in advance.

5. Initially all jobs and AGVs are available at zero time.

6. Number of AGVs are known

7. Layout and Flow path are known.

8. Assume design and setup times have already been considered.

9. Pallet and other necessary equipment are allocated.

10. The speed of AGV kept at $40 \mathrm{~m} / \mathrm{min}$. 


\subsection{Input data}

The input data are adopted from the paper by Bilge and Ulusoy (1995). Travel time data for the example problem are given in Table 1. Table 2 gives the 10 job sets data, each job contains five to eight different jobs and each job is processed on three to five machines and the number besides machine number is process time of specific job (Bilge \& Ulusoy 1995). The load/unload (L/U) station are given as distribution center and collection center for parts.

Table 1

Example problem travel time data for four layouts in meters

\begin{tabular}{cccccc}
\hline \multicolumn{7}{c}{ Layout-1 } \\
\hline From/To & L/U & M1 & M2 & M3 & M4 \\
\hline L/U & 0 & 6 & 8 & 10 & 12 \\
M1 & 12 & 0 & 6 & 8 & 10 \\
M2 & 10 & 6 & 0 & 6 & 8 \\
M3 & 8 & 8 & 6 & 0 & 6 \\
M4 & 6 & 10 & 8 & 6 & 0 \\
\hline \multicolumn{7}{c}{ Layout-3 } \\
\hline From/To & L/U & M1 & M2 & M3 & M4 \\
\hline L/U & 0 & 2 & 4 & 10 & 12 \\
M1 & 12 & 0 & 2 & 8 & 10 \\
M2 & 10 & 12 & 0 & 6 & 8 \\
M3 & 4 & 6 & 8 & 0 & 2 \\
M4 & 2 & 4 & 6 & 12 & 0 \\
\hline
\end{tabular}

\begin{tabular}{cccccc}
\hline \multicolumn{7}{c}{ Layout-2 } \\
\hline From/To & L/U & M1 & M2 & M3 & M4 \\
\hline L/U & 0 & 4 & 6 & 8 & 6 \\
M1 & 6 & 0 & 2 & 4 & 2 \\
M2 & 8 & 12 & 0 & 2 & 4 \\
M3 & 6 & 10 & 12 & 0 & 2 \\
M4 & 4 & 8 & 10 & 12 & 0 \\
\hline \multicolumn{7}{|c}{ Layout-4 } \\
\hline From/To & L/U & M1 & M2 & M3 & M4 \\
\hline L/U & 0 & 4 & 8 & 10 & 14 \\
M1 & 18 & 0 & 4 & 6 & 10 \\
M2 & 20 & 14 & 0 & 8 & 6 \\
M3 & 12 & 8 & 6 & 0 & 6 \\
M4 & 14 & 14 & 12 & 6 & 0 \\
\hline
\end{tabular}

Table 2

Job set data with process time used in example problems

\begin{tabular}{|c|c|c|}
\hline JobSet-1 & JobSet-2 & JobSet-3 \\
\hline Job 1: M1(8); M2(16); M4(12) & Job 1: Ml(10); M4(18) & Job 1:Ml(16); M3(15) \\
\hline Job 2: M1(20); M3(10); M2(18) & Job 2: M2(10); M4(18) & Job 2:M2(18); M4(15) \\
\hline Job 3: M3(12); M4(8); Ml(15) & Job 3: Ml(10); M3(20); & Job 3:M1(20); M2(10) \\
\hline Job 4: M4(14); M2(18) & Job 4: M2(10); M3(15); M4(12) & Job 4:M3(15); M4(10) \\
\hline \multirow[t]{2}{*}{ Job 5: M3(10); Ml(15) } & Job 5: Ml(10); M2(15); M4(12) & Job 5:M1(8);M2(10);M3(15);M4(17) \\
\hline & Job 6: M1(10); M2(15); M3(12) & Job 6: M2(10);M3(15);M4(8);Ml(15 \\
\hline JobSet-4 & JobSet-5 & JobSet-6 \\
\hline Job1: M4(11); M1(10); M2(7) & Job 1: M1(6);M2(12);M4(9) & Job 1: M1(9); M2(11); M4(7) \\
\hline Job2: M3(12); M2(10); M4(8) & Job 2: M1(18);M3(6); M2(15) & Job 2: M1(19); M2(20); M4(13) \\
\hline Job3: M2(7); M3(10); Ml(9); M3(8) & Job 3: M3(9);M4(3);Ml(12) & Job 3: M2(14); M3(20); M4(9) \\
\hline Job4: M2(7); M4(8); M1(12);M2(6) & Job 4: M4(6);M2(15) & Job 4: M2(14); M3(20); M4(9) \\
\hline \multirow[t]{2}{*}{ Job5:M1(9);M2(7);M4(8);M2(10);M3(8) } & Job 5: M3(3);M1(9) & Job 5: M1(11); M3(16); M4(8) \\
\hline & & Job 6: Ml(10); M3(12); M4(10) \\
\hline JobSet-7 & JobSet-8 & JobSet-9 \\
\hline Job 1: Ml(6); M4(6) & Job 1: M2(12); M3(21);M4(11) & Job 1: M3(9);M1(12);M2(9);M4(6) \\
\hline Job 2: M2(11); M4(9) & Job 2: M2(12); M3(21);M4(11) & Job 2: M3(16);M2(11); M4(9) \\
\hline Job 3: M2(9); M4(7) & Job 3: M2(12); M3(21);M4(11) & Job 3: Ml(21); M2(18); M4(7) \\
\hline Job 4: M3(16); M4(7) & Job 4: M2(12); M3(21);M4(11) & Job 4: M2(20); M3(22); M4(11) \\
\hline Job 5: M1(9); M3(18) & Job 5: M1(10); M2(14);M3(18);M4(9) & Job 5:M3(14);M1(16);M2(13);M4(9) \\
\hline Job 6: M2(13); M3(19); M4(6) & Job 6: Ml(10);M2(14); M3(18);M4(9) & \\
\hline \multicolumn{3}{|l|}{ Job 7: Ml(10); M2(9); M3(13) } \\
\hline \multicolumn{3}{|l|}{ Job 8: M1(11); M2(9); M4(8) } \\
\hline \multicolumn{3}{|l|}{ JobSet-10 } \\
\hline \multicolumn{3}{|c|}{ Job1:M1(11);M3(19);M2(16);M4(13), Job2: M2(21);M3(16); M4(14) } \\
\hline \\
\hline \multicolumn{3}{|c|}{$\begin{array}{ll}\text { Job3:M3(8); M2(10); M1(14); M4(9), Job4: M2(13); M3(20); M4(10) } \\
\text { Job5: M1(9); M3(16); M4(18), } \quad \text { Job6:M2(19);M1(21); M3(11);M4(15) }\end{array}$} \\
\hline
\end{tabular}




\subsection{Objective Function}

Minimization of makespan is objective function and the formulas used are given below:

$$
\begin{aligned}
& \text { Operation completion time }\left(O_{i j}\right)=T_{i j}+P_{i j}, \\
& \text { Job completion time }\left(C_{i}\right)=\sum_{i=1}^{n} O_{i j} \\
& \text { Makespan }=\max \left(C_{1}, C_{2}, C_{3}, \ldots \ldots \ldots . C_{n}\right)
\end{aligned}
$$

where $j=$ operation, $i=$ job,$T_{i j}=$ travelling time, $P_{i j}=$ operation processing time.

\subsection{Vehicle scheduling methodology}

Two AGVs are considered for simultaneous scheduling in FMS and both the vehicles are assigned randomly for the first two operations. From third operation onwards, the following algorithm is used for selecting one of the two vehicles.

1. Identify the AGVs location and ready time.

2. Vehicle empty traveling time is to be calculated.

3. To obtain the completion time of vehicle add empty travel time of vehicle to the ready time.

4. If necessary vehicle wait until completing the previous operation.

5. Consider maximum value of vehicle empty travel time and previous operation completion time for further calculations.

6. To obtain the vehicle loaded travel time consider the vehicle from previous operation machine to present operation machine.

7. To obtain the completion time of vehicle loaded trip add the maximum value obtained in step 5 .

8. The AGV is ready for the next operation after completing the loaded trip and the algorithm is repeats at every operation.

To reduce the waiting time and improve the resource utilizations this vehicle heuristic helps in FMS and the flow chart for machine and automated guided vehicle is given in Fig. 1.

\section{Fuzzy sets heuristic algorithm}

Fuzzy Heuristic (FH) algorithm is used for this particular scheduling problem. FH was suggested by Heydari and Mohammadi (2010) and was developed initially to find solutions for small size NP hard problems. According to Johnson's rule all jobs are associated to one of two sets $U=\left\{j / t_{j 1}<t_{j 2}\right\}$ or set $V=\left\{j / t_{j 1} \geq t_{j 2}\right\}$, on the other hand, job processing time on the two machine problem will be changed increasingly (U) or decreasingly (V). Here we went to extended Johnson's rule for more than two machines. In Fuzzy heuristic algorithm fuzzy set $U$ with membership function $u_{u^{-}}(J)$ and fuzzy set V with member ship function $u_{v^{-}}(J)$ are considered. The proposed algorithm is as follows,

Step 1: Calculate $S_{j 1}=\sum_{K=1}^{a} t_{j k}$ and $S_{j 2}=\sum_{K=a}^{n} t_{j k}$, where $a=\frac{n}{2}+1 \quad$ for each Job 'J'

Step 2: Calculate $u_{u^{-}}(J)=\frac{s_{j 1}}{S_{j 1}+S_{j 2}}$ and $u_{v^{-}}(J)=\frac{s_{j 1}}{S_{j 1}+S_{j 2}}$

Step 3: Arrange members of U decreasingly according $u_{u^{-}}(J)$ to $t_{j 1}$ or arrange members of V increasingly according to $u_{v^{-}}(J)$

Step 4: A sequence of arranged $\mathrm{U}$ or $\mathrm{V}$ will be an acceptable schedule. 


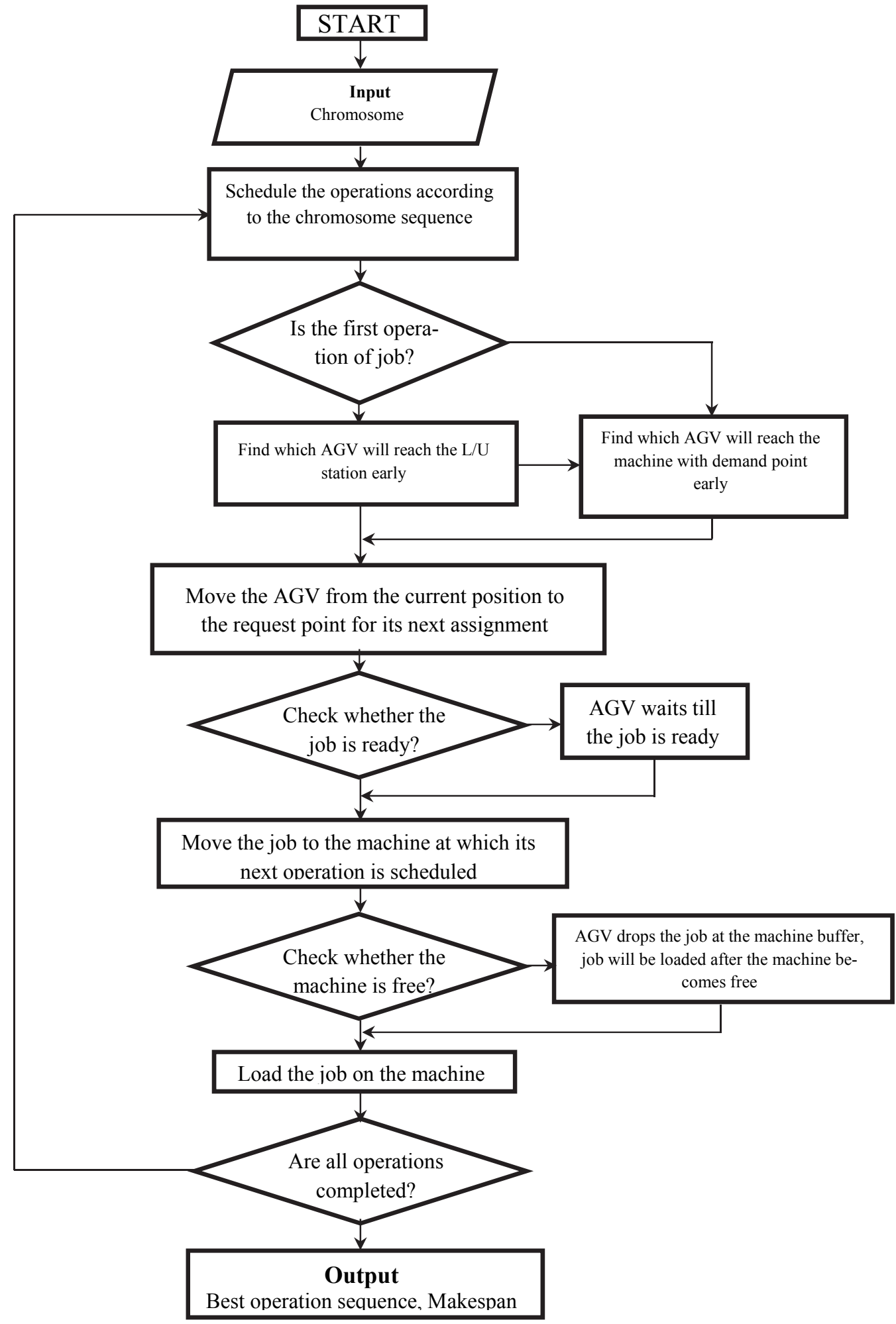

Fig. 1. Machine and automated guided vehicle scheduling flow chart.

\section{Implementation of fuzzy heuristic algorithm to simultaneous scheduling problems}

Developed Heuristic Algorithm to solve NP-hard problems arises in the scheduling problems. The proposed algorithms are implemented to the scheduling problems. The details of which are presented here 
below. For execution of Fuzzy Heuristic Algorithm, job set number 5 and layout numbers 1 are considered.

Step 1: Job set is considered

\begin{tabular}{ccccc}
\hline $\begin{array}{c}\text { Job } \\
\text { Set No }\end{array}$ & $\begin{array}{c}\text { Layout } \\
\text { Number }\end{array}$ & $\begin{array}{c}\text { Total No of } \\
\text { Jobs }\end{array}$ & $\begin{array}{c}\text { Total No of } \\
\text { operations }\end{array}$ & \multicolumn{1}{c}{$\begin{array}{c}\text { Sequence of } \\
\text { Machines with Job Number }\end{array}$} \\
& & & & $\begin{array}{l}1: 1-2-4 \\
2: 1-3-2 \\
5\end{array}$ \\
& 1 & 5 & 13 & $3: 3-4-1$ \\
& & & $4: 4-2$ \\
& & & $5: 3-1$
\end{tabular}

Step 2: For each Job 'J' calculate $S_{j 1}=\sum_{K=1}^{a} t_{j k}$ and $S_{j 2}=\sum_{K=a}^{n} t_{j k}$, where $a=\frac{n}{2}+1$

\begin{tabular}{ccccc}
\hline $\begin{array}{c}\text { M. No } \\
\text { Job.No }\end{array}$ & 1 & 2 & 3 & 4 \\
\hline 1 & 6 & 12 & 0 & 9 \\
2 & 18 & 15 & 6 & 0 \\
3 & 12 & 0 & 9 & 3 \\
4 & 0 & 15 & 0 & 6 \\
5 & 9 & 0 & 3 & 0 \\
\hline
\end{tabular}

For job set 5 calculate $S_{j 1}=\sum_{K=1}^{a} t_{j k}$ and $S_{j 2}=\sum_{K=a}^{n} t_{j k}$

where $a=\frac{n}{2}+1, \mathrm{n}=$ no of machines, in this problem $\mathrm{n}=4$ and $\mathrm{a}=3$

For job '1' $\boldsymbol{S}_{\boldsymbol{j} 1}$ and $\boldsymbol{S}_{\boldsymbol{j} 2}$ are follows

$S_{j 1}=\sum_{K=1}^{3} t_{j k}=6+12+0=18$

$S_{j 2}=\sum_{K=3}^{4} t_{j k}=0+9=9$

In the same manner for all jobs $\boldsymbol{S}_{\boldsymbol{j} 1}$ and $\boldsymbol{S}_{\boldsymbol{j} \mathbf{2}}$ are

\begin{tabular}{lll}
\hline Job & $\boldsymbol{S}_{\boldsymbol{j} \mathbf{1}}$ & $\boldsymbol{S}_{\boldsymbol{j} \mathbf{2}}$ \\
\hline 1 & 18 & 9 \\
2 & 39 & 6 \\
3 & 21 & 12 \\
4 & 15 & 6 \\
5 & 12 & 3 \\
\hline
\end{tabular}

Step 3: Calculate $u_{u^{-}}(J)=\frac{s_{j 1}}{s_{j 1}+S_{j 2}}$ and $u_{v^{-}}(J)=\frac{s_{j 1}}{s_{j 1}+S_{j 2}}$

For job ' 1 ' $\mu_{u}(J)$ and $\mu_{v}(J)$ are follows

$u_{u^{-}}(J)=\frac{S_{j 1}}{S_{j 1}+S_{j 2}}=18 / 18+9=0.666$

$u_{v^{-}}(J)=\frac{S_{j 1}}{S_{j 1}+S_{j 2}}=9 / 18+9=0.333$

In the same manner for all jobs $\mu_{u}(J)$ and $\mu_{v}(J)$ are 


\begin{tabular}{ccccc}
\hline Job & $\boldsymbol{S}_{\boldsymbol{j} \mathbf{1}}$ & $\boldsymbol{S}_{\boldsymbol{j} \mathbf{2}}$ & $\mu_{u}(J)$ & $\mu_{v}(J)$ \\
\hline 1 & 18 & 9 & 0.666 & 0.333 \\
2 & 39 & 6 & 0.866 & 0.133 \\
3 & 21 & 12 & 0.636 & 0.363 \\
4 & 15 & 6 & 0.714 & 0.285 \\
5 & 12 & 3 & 0.800 & 0.200 \\
\hline
\end{tabular}

Step 4: Arrange members of $U$ decreasingly according to $u_{u^{-}}(J)$ and $t_{j 1}$ or arrange members of V increasingly according to $u_{v^{-}}(J)$

According to $\mu_{u}(J)$ the job order is

\begin{tabular}{lccccc}
\hline Job & 1 & 2 & 3 & 4 & 5 \\
\hline$\mu_{u}(J)$ & 0.666 & 0.866 & 0.636 & 0.714 & 0.800 \\
Priority & 2 & 5 & 1 & 3 & 4 \\
\hline
\end{tabular}

According to $\mu_{v}(J)$ the job order is

\begin{tabular}{lccccc}
\hline Job & 1 & 2 & 3 & 4 & 5 \\
\hline$\mu_{u}(J)$ & 0.333 & 0.133 & 0.363 & 0.285 & 0.200 \\
Priority & 2 & 5 & 1 & 3 & 4 \\
\hline
\end{tabular}

Step 5: A sequence of arranged $\mathrm{U}$ or $\mathrm{V}$ will be an acceptable schedule

As per the fuzzy sets heuristic algorithm the operational sequence as

$$
7-8-9-1-2-3-10-11-12-13-4-5-6
$$

The makespan calculation for above sequence is shown in Table 3.

Table 3

Operations schedule through FUZZY (for Problem set 5 and layout 1)

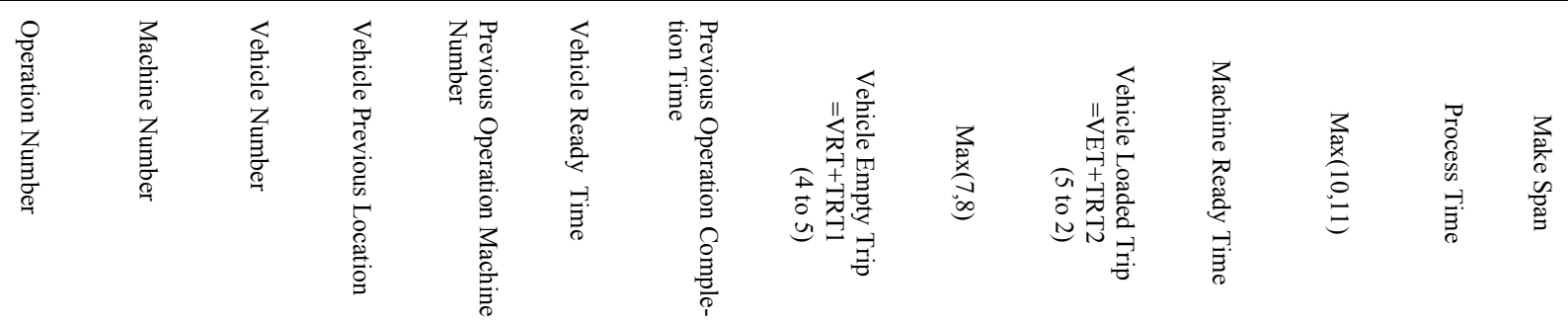

\begin{tabular}{ccccccccccccccc}
\hline$(1)$ & $(2)$ & $(3)$ & $(4)$ & $(5)$ & $(6)$ & $(7)$ & $(8)$ & $(9)$ & $(10)$ & $(11)$ & $(12)$ & $(13)$ & $(14)$ \\
7 & 3 & 1 & $\mathrm{~L} / \mathrm{U}$ & $\mathrm{L} / \mathrm{U}$ & 0 & 0 & 0 & 0 & 10 & 0 & 10 & 9 & 19 \\
8 & 4 & 2 & $\mathrm{~L} / \mathrm{U}$ & 3 & 0 & 19 & 10 & 19 & 25 & 0 & 25 & 3 & 28 \\
9 & 1 & 1 & 3 & 4 & 10 & 28 & 16 & 28 & 38 & 0 & 38 & 12 & 50 \\
1 & 1 & 2 & 4 & $\mathrm{~L} / \mathrm{U}$ & 25 & 0 & 31 & 31 & 37 & 50 & 50 & 6 & 56 \\
2 & 2 & 2 & 1 & 1 & 37 & 56 & 37 & 56 & 62 & 0 & 62 & 12 & 74 \\
3 & 4 & 1 & 1 & 2 & 38 & 74 & 44 & 74 & 82 & 28 & 82 & 9 & 91 \\
10 & 4 & 2 & 2 & $\mathrm{~L} / \mathrm{U}$ & 62 & 0 & 72 & 72 & 84 & 91 & 91 & 6 & 97 \\
11 & 2 & 1 & 4 & 4 & 82 & 97 & 82 & 97 & 105 & 74 & 105 & 15 & 120 \\
12 & 3 & 2 & 4 & $\mathrm{~L} / \mathrm{U}$ & 84 & 0 & 90 & 90 & 100 & 19 & 100 & 3 \\
13 & 1 & 2 & 3 & 3 & 100 & 103 & 100 & 103 & 111 & 56 & 111 & 9 & 120 \\
4 & 1 & 1 & 2 & $\mathrm{~L} / \mathrm{U}$ & 105 & 0 & 115 & 115 & 121 & 120 & 121 & 18 & 139 \\
5 & 3 & 2 & 1 & 1 & 111 & 139 & 111 & 139 & 147 & 103 & 147 & 6 & 153 \\
6 & 2 & 1 & 1 & 3 & 121 & 153 & 129 & 153 & 159 & 120 & 159 & 15 & 174 \\
\hline
\end{tabular}

Table 3 shows operation scheduling through fuzzy heuristic algorithm for job set 5 layout 1 is shown. From the table it is observed that operation 7 on machine 3 is completed by 19 min hence $8^{\text {th }}$ operation will start after 
completion of $7^{\text {th }}$ operation on machine 3 . In case of job set 5 and layout 1 operation 8 on machine 4 is completed by 28 min hence $9^{\text {th }}$ operation on machine 1 will start after completion of $8^{\text {th }}$ operation on machine 4 . Similarly no operation on the particular machine will start until the operation on the machine is completed. From the vehicle heuristic algorithm for first two operations AGVs are selected randomly in case of third operation AGV ' 1 ' is selected basing on the availability of AGV with minimum travel time this constraint will be taking care in the algorithm. For job set 5 and layout 1 the operational completion time (makespan) is 174. Scheduling problems in FMS (Bilge \& Ulusoy, 1995) are solved through JAVA programming.

\section{Results and discussion}

The simultaneous scheduling of machines and AGVs procedure through fuzzy heuristic algorithm have been developed in the 'JAVA' language. Processing time of the machines and travel time for AGVs are given as input. For 82 test problems JAVA code gives the optimal sequence of jobs. While generating the example problems the ratio of travel time and process time is the main criterion because of interaction of AGVs and machine with travel time and process time is the major parameter (Bilge \& Ulusoy, 1995). Four different layouts are generated with each layout having four machines through loop or ladder or combination of both (Kusiaka, 1985). 82 example problems are generated with different combinations of ten job sets and four layouts. Problems with $\mathrm{t} / \mathrm{p}>0.25$ are presented in Table 4 , and problems with $\mathrm{t} / \mathrm{p}<0.25$ are presented in Table 5 .

\section{Table 4}

Comparison of make span values with $\mathrm{t} / \mathrm{p}>0.25$

\begin{tabular}{|c|c|c|c|c|c|c|}
\hline Job. No & $\mathrm{t} / \mathrm{p}$ & FCFS & SPT & LPT & $\mathrm{NEH}$ & FUZZY \\
\hline 1.1 & 0.59 & 173 & 193 & 177 & 165 & 208 \\
\hline 2.1 & 0.61 & 158 & 158 & 177 & 169 & 170 \\
\hline 3.1 & 0.59 & 202 & 224 & 198 & 195 & 211 \\
\hline 4.1 & 0.91 & 263 & 267 & 264 & 260 & 268 \\
\hline 5.1 & 0.85 & 148 & 164 & 148 & 147 & 174 \\
\hline 6.1 & 0.78 & 231 & 240 & 227 & 225 & 233 \\
\hline 7.1 & 0.78 & 195 & 210 & 201 & 173 & 196 \\
\hline 8.1 & 0.58 & 261 & 261 & 266 & 261 & 261 \\
\hline 9.1 & 0.61 & 270 & 277 & 268 & 259 & 273 \\
\hline 10.1 & 0.55 & 308 & 308 & 310 & 305 & 315 \\
\hline 1.2 & 0.47 & 143 & 173 & 165 & 147 & 188 \\
\hline 2.2 & 0.49 & 124 & 124 & 130 & 116 & 127 \\
\hline 3.2 & 0.47 & 162 & 188 & 160 & 154 & 178 \\
\hline 4.2 & 0.73 & 217 & 223 & 224 & 215 & 232 \\
\hline 5.2 & 0.68 & 118 & 144 & 131 & 117 & 156 \\
\hline 6.2 & 0.54 & 180 & 169 & 165 & 158 & 175 \\
\hline 7.2 & 0.62 & 149 & 160 & 149 & 136 & 139 \\
\hline 8.2 & 0.46 & 181 & 181 & 198 & 181 & 181 \\
\hline 9.2 & 0.49 & 250 & 249 & 244 & 205 & 249 \\
\hline 10.2 & 0.44 & 290 & 288 & 287 & 274 & 274 \\
\hline 1.3 & 0.52 & 145 & 175 & 167 & 145 & 190 \\
\hline 2.3 & 0.54 & 130 & 130 & 136 & 122 & 133 \\
\hline 3.3 & 0.51 & 160 & 190 & 162 & 158 & 176 \\
\hline 4.3 & 0.8 & 233 & 237 & 230 & 226 & 234 \\
\hline 5.3 & 0.74 & 120 & 146 & 133 & 117 & 156 \\
\hline 6.3 & 0.54 & 182 & 171 & 167 & 160 & 177 \\
\hline 7.3 & 0.68 & 155 & 166 & 151 & 138 & 141 \\
\hline 8.3 & 0.5 & 183 & 183 & 200 & 183 & 183 \\
\hline 9.3 & 0.53 & 252 & 251 & 246 & 207 & 251 \\
\hline 10.3 & 0.49 & 293 & 294 & 293 & 280 & 280 \\
\hline 1.4 & 0.74 & 189 & 207 & 189 & 189 & 228 \\
\hline 2.4 & 0.77 & 174 & 174 & 174 & 169 & 190 \\
\hline 3.4 & 0.74 & 220 & 250 & 212 & 213 & 225 \\
\hline 4.4 & 1.14 & 301 & 301 & 298 & 298 & 294 \\
\hline 5.4 & 1.06 & 171 & 189 & 171 & 171 & 193 \\
\hline 6.4 & 0.78 & 249 & 252 & 237 & 234 & 243 \\
\hline 7.4 & 0.97 & 217 & 242 & 151 & 192 & 232 \\
\hline 8.4 & 0.72 & 285 & 285 & 200 & 285 & 285 \\
\hline 9.4 & 0.76 & 292 & 311 & 290 & 285 & 295 \\
\hline 10.4 & 0.69 & 350 & 350 & 345 & 345 & 353 \\
\hline
\end{tabular}


From the table job number 1.1 means job set 1 and layout 1 , from the Table 5 another digit appears as 2.10, which means job set 2 layout 1 with process time double and travel time halved or 2.41 it means job set 2 layout 4 with tripled process time and travel time halved. From Table 4 it can be observed that, out of 40 problems, 6 problems give better results using fuzzy heuristic algorithm when compared with all other four algorithms and it can also be observed from Table 5 that out of 42 problems, 7 problems give better results using fuzzy when compared with all other four algorithms. When comparing the results of fuzzy algorithm with FCFS by Nageswararao et al. (2017), it is observed that Fuzzy heuristic gives better results for 14 problems out of 40 problems in the case of ti $/ \mathrm{pi}>0.25$ and gives better results for 23 problems out of 42 problems in the case of ti $/ \mathrm{pi}<0.25$. Similarly when comparing the results with SPT, LPT and NEH by Prakashbabu et al (2018), Fuzzy heuristic gives better results for 22,12,7 problems respectively out of 40 problems in the case of $t_{i} / p_{i}>0.25$ and gives better results for 23,22 and 7 problems respectively out of 42 problems in the case of $\mathrm{t}_{\mathrm{i}} / \mathrm{p}_{\mathrm{i}}<0.25$.

Table 5

Comparison of make span values with $\mathrm{t} / \mathrm{p}<0.25$

\begin{tabular}{|c|c|c|c|c|c|c|}
\hline Job.No & $\mathrm{t} / \mathrm{p}$ & FCFS & SPT & LPT & $\mathrm{NEH}$ & FUZZY \\
\hline 1.10 & 0.15 & 207 & 248 & 252 & 207 & 278 \\
\hline 2.10 & 0.15 & 217 & 217 & 225 & 185 & 208 \\
\hline 3.10 & 0.15 & 257 & 327 & 282 & 255 & 300 \\
\hline 4.10 & 0.15 & 303 & 328 & 317 & 277 & 352 \\
\hline 5.10 & 0.21 & 152 & 190 & 187 & 154 & 225 \\
\hline 6.10 & 0.16 & 304 & 281 & 297 & 272 & 294 \\
\hline 7.10 & 0.19 & 231 & 240 & 264 & 213 & 235 \\
\hline 8.10 & 0.14 & 338 & 338 & 347 & 332 & 338 \\
\hline 9.10 & 0.15 & 390 & 367 & 359 & 324 & 382 \\
\hline 10.10 & 0.14 & 452 & 429 & 444 & 398 & 393 \\
\hline 1.20 & 0.12 & 194 & 238 & 246 & 197 & 268 \\
\hline 2.20 & 0.12 & 194 & 194 & 206 & 167 & 187 \\
\hline 3.20 & 0.12 & 241 & 311 & 270 & 241 & 285 \\
\hline 4.20 & 0.12 & 285 & 312 & 298 & 248 & 340 \\
\hline 5.20 & 0.17 & 142 & 180 & 184 & 143 & 217 \\
\hline 6.20 & 0.12 & 292 & 260 & 284 & 251 & 277 \\
\hline 7.20 & 0.15 & 212 & 218 & 249 & 188 & 210 \\
\hline 8.20 & 0.11 & 306 & 319 & 334 & 306 & 306 \\
\hline 9.20 & 0.12 & 380 & 355 & 347 & 309 & 372 \\
\hline 10.20 & 0.11 & 445 & 423 & 439 & 388 & 384 \\
\hline 1.30 & 0.13 & 195 & 239 & 247 & 196 & 169 \\
\hline 2.30 & 0.13 & 197 & 197 & 209 & 170 & 190 \\
\hline 3.30 & 0.13 & 240 & 312 & 271 & 240 & 284 \\
\hline 4.30 & 0.13 & 292 & 317 & 301 & 255 & 339 \\
\hline 5.30 & 0.18 & 141 & 181 & 183 & 143 & 216 \\
\hline 6.30 & 0.24 & 296 & 261 & 285 & 252 & 278 \\
\hline 7.30 & 0.17 & 215 & 221 & 250 & 191 & 213 \\
\hline 8.30 & 0.13 & 307 & 320 & 335 & 307 & 307 \\
\hline 9.30 & 0.13 & 381 & 356 & 348 & 310 & 373 \\
\hline 10.30 & 0.12 & 448 & 426 & 442 & 391 & 387 \\
\hline 1.40 & 0.18 & 213 & 255 & 254 & 213 & 288 \\
\hline 2.41 & 0.13 & 307 & 307 & 319 & 267 & 293 \\
\hline 3.40 & 0.18 & 261 & 330 & 282 & 258 & 305 \\
\hline 3.41 & 0.12 & 370 & 476 & 411 & 310 & 435 \\
\hline 4.41 & 0.19 & 434 & 471 & 451 & 393 & 504 \\
\hline 5.41 & 0.18 & 218 & 269 & 270 & 222 & 321 \\
\hline 6.40 & 0.19 & 310 & 288 & 299 & 275 & 303 \\
\hline 7.40 & 0.24 & 239 & 251 & 270 & 221 & 246 \\
\hline 7.41 & 0.16 & 329 & 344 & 385 & 224 & 332 \\
\hline 8.40 & 0.18 & 343 & 343 & 349 & 339 & 343 \\
\hline 9.40 & 0.19 & 396 & 379 & 370 & 325 & 388 \\
\hline 10.40 & 0.17 & 466 & 445 & 455 & 415 & 408 \\
\hline
\end{tabular}

\section{Conclusions}

In this work the optimal sequence of machine and AGVs in FMS have been determined through fuzzy heuristic algorithm. The proposed algorithm provides the flow requirements of machine and AGVs simultaneously. This work mainly concentrated to integrate the material handling scheduling with machines. 
It has observed that fuzzy heuristic algorithm is an effective method while generating optimal solutions in FMS from Table 4 and Table 5. Whereas process time and travel time are comparable, the proposed algorithm has given improvement in scheduling. For the simultaneous scheduling work fuzzy heuristic is suitable tool rather than non-traditional techniques. Since, the proposed algorithm gives assurance for improvement of scheduling in FMS environment, this methodology can be extended for several multiobjectives criteria like automated storage and retrieval systems and robots can also be included with machine and AGVs scheduling of FMS in future work.

\section{Acknowledgments}

The authors extremely acknowledge the resource from DST-SERB, Government of India (Sanction No: SB/EMEQ-501/2014) for finishing up this R \& D activity.

\section{References}

Babu, K., Babu, V., \& Medikondu, N. (2018). Implementation of heuristic algorithms to synchronized planning of machines and AGVs in FMS. Management Science Letters, 8(6), 543-554.

Bilge, Ü., \& Ulusoy, G. (1995). A time window approach to simultaneous scheduling of machines and material handling system in an FMS. Operations Research, 43(6), 1058-1070.

Campbell, H.G., Dudek, R.A., \& Smith, M.L. (1970). A heuristic algorithm for the n-job m-machine sequencing problem. Management Science, 16(10), B630-637

Fang, K., Uhan, N., Zhao, F., \& Sutherland, J. (2011). A new shop scheduling approach in support of sustainable manufacturing. 18th CIRP LCE Conference, Braunschweig, 305-310.

Gupta, J. N. (1971). A functional heuristic algorithm for the flowshop scheduling problem. Journal of the Operational Research Society, 22(1), 39-47.

Han, M.H., \& McGinnis, L.F. (1989) Flow control in flexible manufacturing: minimization of stock out cost. International Journal of Production Research, 27(4), 701-715.

Heydari, M., \& Mohammadi, E. (2010). A fuzzy heuristic algorithm for the flow shop scheduling problem. The Journal of Mathematics and Computer Science, 4, 349-354.

Johnson, S. M. (1954). Optimal two- and three-Stage production schedules with setup times included. Naval Logistics Quarterly, 1(1), 61-68.

Kusiak, A. (1986). FMS scheduling-a crucial element in an expert system control architecture. IEEE International Conference on Robotics and Automation, 653-658.

Modrák, V., \& Pandian, R. S. (2010). Flow shop scheduling algorithm to minimize completion time for n-jobs m-machines problem. Tehnicki vjesnik, 17(3), 273-2783.

Nageswararao, M., Narayanarao, K., \& Rangajanardhana, G. (2017). Integrated scheduling of machines and AGVs in FMS by using dispatching rules. Journal of Production Engineering, 20(1), 75-84.

Nasr, N., \& Elsayed, E. A. (1990). Job shop scheduling with alternative machines. The international journal of production research, 28(9), 1595-1609.

Nawaz, M., Enscore, E., \& Ham, I. (1983). A heuristic algorithm for the m machine n job flow shop sequence problem. Omega, 11(1), 91-95.

Pach, C., Berger, T., Sallez, Y., Bonte, T., Adam, E., \& Trentesaux, D. (2014). Reactive and energyaware scheduling of flexible manufacturing systems using potential fields. Computers in Industry, 65(3), 434-448.

Palmer, D. S. (1965). Sequencing jobs through a multi-stage process in the minimum total time-a quick method of obtaining a near optimum. Journal of the Operational Research Society, 16(1), 101-107.

Rathinam, B., Govindan, K., Neelakanden, B., \& Raghavan S.S. (2015). Rule based heuristic approach for minimizing total flow time in permutation flow shop scheduling. Tehnički vjesnik-Tehnical Gazette, 22(1), 25-32.

Ruiz, R., \& Stützle, T. (2007). A simple and effective iterated greedy algorithm for the permutation flowshop scheduling problem. European Journal of Operational Research, 177(3), 2033-2049. 
Sabuncuoglu, I., \& Hommertzheim, D. L. (1993). Experimental investigation of an FMS due-date scheduling problem: Evaluation of machine and AGV scheduling rules. International Journal of Flexible Manufacturing Systems, 5(4), 301-323.

Salido, M. A., Escamilla, J., Barber, F. \& Giret, A. (2017). Rescheduling in job-shop problems for sustainable manufacturing systems. Journal of Cleaner Production, 162, S121-S132.

Semančo, P., \& Modrák, V. (2012). A comparison of constructive heuristics with the objective of minimizing makespan in the flow-shop scheduling problem. Acta Polytechnica Hungarica, 9(5), 177-190.

Stecke, K. E. (1985). Design, planning, scheduling, and control problems of flexible manufacturing systems. Annals of Operations research, 3(1), 1-12.

Vallada, E., \& Ruiz, R. (2009). Cooperative metaheuristics for the permutation flow shop scheduling problem. European Journal of Operational Research, 193(2), 365-376.

Zupan, H., Herakovic, N., Starbek, M., \& Kusar, J. (2016). Hybride algorithm based on priority rules for simulation of workshop production. International Journal of Simulation Modelling, 15(1), 29-41.

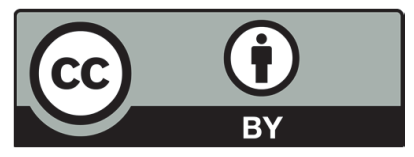

(C) 2018 by the authors; licensee Growing Science, Canada. This is an open access article distributed under the terms and conditions of the Creative Commons Attribution (CCBY) license (http://creativecommons.org/licenses/by/4.0/). 